\title{
PERBANDINGAN PRESTASI BELAJAR METODE PEMBELAJARAN KONVENSIONAL DENGAN METODE PEMBELAJARAN PEER TEACHING PADA MATA KULIAH ANATOMI DAN FISIOLOGI PERKEMIHAN MAHASISWA SEMESTER I AKPER DHARMA HUSADA KEDIRI
}

\author{
Sucipto, Moh Alimansur \\ Akper Dharma Husada Kediri \\ Email: suciptodika@yahoo.com, ali.mansur75@yahoo.co.id
}

\begin{abstract}
ABSTRAK
Pembelajaran yang monoton dan satu arah tidaklah cocok dipraktikkan pada mahasiswa D-III keperawatan sebab sebagai perawat nantinya mempunyai tanggung jawab terhadap keputusan dan tindakan asuhan keperawatan professional, untuk itu diperlukan pembelajaran dengan adanya aktivitas dua arah akan menghasilkan pembelajaran yang lebih menarik dan efektif. metode pembelajaran yang sesuai dengan tujuan instruksional serta pelaksanaannya dilihat dari sarana dan waktu yang tersedia. Salah satunya yaitu metode peer teaching. Tujuan penelitian untuk Untuk mengetahui perbedaan Prestasi Belajar Metode pembelajaran konvensional dengan Metode Peer Teaching pada mata kuliah antomi dan fisiologi Perkemihan. Penelitian ini menggunakan pendekatan komparatif kuantitatif Uji statistic yang digunakan dalam penelitian adalah menggunakan T-Tes. Dengan nilai $\mathrm{P}=0,015$, hasil yang diperoleh menunjukan ada perbedaan Prestasi belajar Mahasiswa Akper Dharma Husada Kediri terhadap mata kuliah Anatomi dan Fisiologi Perkemihan dengan Metode Peer Teaching dan konvensional. Perlu adanya upaya untuk mencoba menanggulangi permasalahan dalam prestasi belajar mahasiswa salah satunya dengan cara menggunakan model pembelajaran yang dianggap lebih efektif dalam pembelajaran dibandingkan dengan model konvensional.
\end{abstract}

Kata Kunci : Peer Teaching, Prestasi belajar, dan metode konvensional

\section{ABSTRACT}

Learning monotonous and one direction does not appropriate practiced in D-III nursing students because as a nurse will have responsibility for decisions and actions of professional nursing care, it is necessary for learning with their two-way activity will produce learning more interesting and effective. Learning methods in accordance with the instructional goals, and implementation views of the means and the time available. One such method of peer teaching. For research purposes to determine the difference Achievement conventional learning methods with Peer Teaching Method course on anatomy and physiology Urinal. This study uses a comparative approach quantitative statistical test used in the study are using T-test. $P=0.015$, the results obtained show no difference in learning achievement Nursing Students Dharma Husada Kediri to the subjects of Anatomy and Physiology Urinal with Peer Teaching and conventional methods. Should the effort to try address the problems of student learning achievement such as by using a learning model that is considered more effective in learning compared to conventional models.

Key word: Peer Teaching, Learning achievement, conventional models 


\section{Pendahuluan}

Mengacu pada Kerangka Kualifikasi Nasional Indonesia (KKNI) bahan kajian kompetensi pada Akper Dharma Husada Kediri meliputi adalah perawat lulusan jenjang Diploma III Keperawatan berperan sebagai perawat terampil dalam menyelesaikan masalah keperawatan secara mandiri dan berkelompok yang direncanakan sesuai dengan standar asuhan keperawatan, dengan kemampuan menerima tanggung jawab terhadap keputusan dan tindakan asuhan keperawatan professional, sesuai dengan lingkup praktik dan hukum/ peraturan perundangan, Beban studi Akper Dharma Husada Kediri adalah118 SKS (LPPM, 2014). Pada mata kuliah ilmu biomedik Dasar salah satunya adalah mata kuliah anatomi fisiologi, merupakan mata kuliah dasar yang menjadi landasan matakuliah pada semester selanjutnya sehingga mahasiswa wajib mempunyai kemampuan untuk menguasi mata kuliah tersebut. Mata kuliah anatomi dan fisiologi diangap sebagian mahasiswa cukup sulit dikuasi salah satunya anatami dan fisiologi perkemihan (------------, 2014).

Mahasisawa Akper Dharma Husada Kediri untuk hasil evaluasi mata kuliah anatomi dan fisiologi perkemihan pada tahun 2012 rata-rata nilai 62, tahun 2013 rata-rata nilai 55, dari angka tersebut menunjukan penurunan nilai. Hal ini banyak faktor sebagai penyebab turunnya nilai. Metode pembelajaran yang di laksanakan saat ini menggunakan metode konvensional antara lain: penggunaan metode ceramah, diskusi, tanya jawab. Metode konvensional memperlihatkan sebagian mahasiswa tidak cukup serius terlibat dalam belajar. Indikator ketidakseriusan misalnya berbicara dengan temannya, bermain-main atau melakukan kegiatan yang tidak relevan dengan mata kuliah yang diajarkan Aktivitas seperti ini sangat tidak menguntungkan bagi mahasiswa itu sendiri karena mahasiswa tidak membangun pengetahuannya melalui pemahaman konsep-konsep. Suwono (1999). Dapat disimpulkan bahwa pembelajaran konvensional lebih terpusat kepada guru/dosen yang mengajar bukan mahasiswa. Pembelajaran yang monoton seperti itu tidaklah cocok dipraktikkan di kelas-kelas, mengingat pembelajaran yang dilakukan dengan adanya aktivitas dua arah akan menghasilkan pembelajaran yang lebih menarik dan efektif. Berdasarkan hal tersebut kemudian muncul berbagai model dan metode pembelajaran yang sesuai dengan tujuan instruksional serta pelaksanaannya dilihat dari sarana dan waktu yang tersedia. Salah satunya yaitu metode peer teaching (mengajar teman sebaya / tutor sebaya) (Ahmadi, 2005).

Pembelajaran model peer teaching adalah metode belajar yang melibatkan siswa secara aktif. Jadi disini satu siswa akan mengajari siswa lain yang mengalami kesulitan dalam memahami materi yang diberikan. Dengan demikian ini memberikan indikasi bahwa keaktifan siswa sangat diperlukan dalam proses belajar mengajar. Keaktifan siswa tersebut sangat besar pengaruhnya terhadap hasil belajarnya (As'ari, 2001).

Berdasarkan hal tersebut di atas maka peneliti bertujuan untuk melakukan penelitian serta guna mendapatkan simpulan yang lebih tajam dan ilmiah maka peneliti tertarik untuk melakukan penelitian mengenai “ Perbandingan Prestasi Belajar metode pembelajaran Konvensional dengan Metode Pembelajaran Peer Teaching pada Mata Kuliah Anatomi dan Fisiologi Perkemihan Mahasiswa Semester I Akper Dharma Husada Kediri”.

\section{Metode}

Penelitian ini menggunakan pendekatan komparatif kuantitatif untuk mengetahui ada tidaknya perbedaan Metode Pembelajaran konvensional dengan metode Pembelajaran Peer Teaching mahasiswa Akper Dharma Husada Kediri Semester I.

Penelitian mulai tanggal 14 Desember 2015 s/d 18 Maret 2016. Lokasi penelitian adalah Perguruan Tinggi Akper Dharma Husada Kediri. Variabel penelitian ini adalah Prestasi belajar pada kelompok kontrol dan perlakuan. Sampel dalam penelitian ini berjumlah 90 dengan sampling jenuh. Metode analisis data yang digunakan dalam penelitian ini adalah dengan menggunakan TTes guna memberi perbedaan Prestasi Belajar metode pembelajaran Konvensional dengan Metode Pembelajaran Peer Teaching pada Mata Kuliah Anatomi dan Fisiologi Perkemihan Mahasiswa Semester I. 


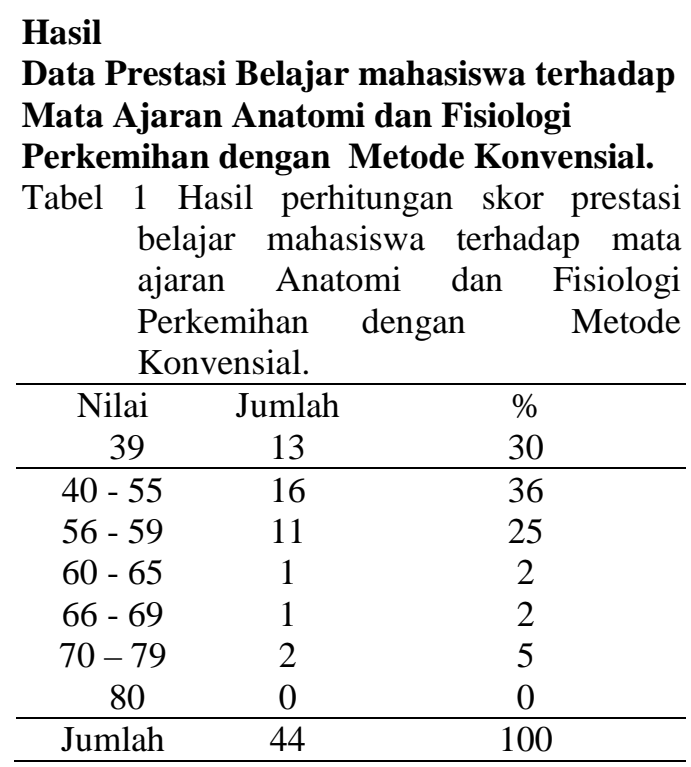

Data primer

Dari tabel diatas dapat kita lihat nilai hasil diperoleh dalam kegiatan belajar mengajar sebelum penerapan metode pembelajaran konvensional pada mata kuliah Anatomi dan Fisiologi Perkemihan . Nilai yang terdapat pada tabel dipergunakan sebagai tolok ukur untuk mengetahui hasil belajar siswa terhadap mata kuliah Anatomi dan Fisiologi Perkemihan. Pada keadaan ini mahasiswa banyak yang mendapat nilai dibawah 39 sebanyak 13 (30\%) dan nilai 40 45 sebanyak $15(36 \%)$, sedangkan yang memperoleh nilai $70-79$ hanya $2(5 \%)$. Hal ini menunjukkan proses belajar mengajar yang dilaksanakan oleh pengajar belum mencapai hasil yang optimal.

\section{Data Prestasi Belajar mahasiswa terhadap Mata Ajaran Anatomi dan Fisiologi Perkemihan dengan Metode Peer Teaching}

Tabel 2 Hasil perhitungan skor prestasi belajar mahasiswa terhadap mata ajaran Anatomi dan Fisiologi Perkemihan dengan Metode Peer Teaching.

\begin{tabular}{ccc}
\hline Nilai & Jumlah & $\%$ \\
\hline$\leq 39$ & 4 & 9 \\
$40-55$ & 20 & 44 \\
$56-59$ & 9 & 20 \\
$60-65$ & 7 & 16 \\
$66-69$ & 0 & 0 \\
$70-79$ & 5 & 11 \\
$\geq 80$ & 0 & 0 \\
\hline Jumlah & 45 & 100 \\
\hline
\end{tabular}

Data primer
Dari tabel diatas dapat kita lihat nilai hasil diperoleh dalam kegiatan belajar mengajar sebelum penerapan metode pembelajaran konvensional pada mata kuliah Anatomi dan Fisiologi Perkemihan . Nilai yang terdapat pada tabel dipergunakan sebagai tolok ukur untuk mengetahui hasil belajar siswa terhadap mata kuliah Anatomi dan Fisiologi Perkemihan. Pada keadaan ini mahasiswa banyak yang mendapat nilai dibawah 39 sebanyak 4 (9\%) dan nilai 40 45 sebanyak $20(44 \%)$, sedangkan yang memperoleh nilai $70-79$ hanya $5(11 \%)$.

\section{Pengujian hipotesis}

Pengujian Hipotesis dalam penelitian menggunakan Analisis T-Tes dengan menggunakan perhitungan statistik yaitu dengan Statistical Packages For Social Science (SPSS) 17.0 for windows.

Berdasarkan hasil pengujian didapatkan nilai $\mathrm{t}=-2,914$ dengan nilai $\mathrm{P}=0,005$ yang menunjukan ada perbedaan Prestasi belajar Mahasiswa Akper Dharma Husada Kediri terhadap mata kuliah Anatomi dan Fisiologi Perkemihan dengan Metode Peer Teaching dan konvensional.

\section{Pembahasan}

Hasil analisis T-Tes menunjukan terdapat perbedaan Prestasi belajar Mahasiswa Akper Dharma Husada Kediri terhadap mata kuliah Anatomi dan Fisiologi Perkemihan dengan Metode Peer Teaching dan Konvensional. Pada metode pembelajaran Peer Teaching terdapat perbedaan nilai yang lebih baik jika dibanding metode pembelajaran Konvensional.

Ini berarti mahasiswa merasa tertarik, senang, termotivasi terhadap pembelajaran metode Peer teaching sebagai pengalaman baru yang menyenangkan, dan pembelajaran model tersebut dapat diterapkan di kelas (Hermawan, 2015).

Kurangnya keaktifan mahasiswa dalam proses pembelajaran akan menimbulkan suasana yang membosankan dan tidak menarik, sehingga mahasiswa yang tadinya mau belajar akan menjadi malas dan tidak semangat (Astika \& Isroah, 2013). Model pembelajaran yang monoton atau yang kita 
sebut konvensional ternyata membuat dampak yang yang negatif bagi mahasiswa antara lain prestasi belajar menjadi tidak optimal (Waluyanti, 2012).

Hal ini sesuai dengan penelitian yang dilakukan oleh Mellita D, 2012 bahwa pembelajaran metode Peer Teaching merupakan Inovasi pembelajaran dapat memunculkan sifat kemandirian, kepemimpinan dan enterpreneurship pada mahasiswa dan dapat diimplementasikan pada kelas bervolume besar. Selain itu tingkat kehadiran mahasiswa dalam kuliah dan diskusi peer teaching tinggi, dan mahasiswa merasa nyaman selama mengikuti kuliah dan diskusi tim.

Juga sesuai dengan pendapat Slavin (1990) bahwa model pembelajaran kooperatif dapat diterapkan pada berbagai mata pelajaran dan berbagai tingkat umur. Penerapan model pembelajaran Peer Teaching (tutor sebaya) telah terbukti efektif dalam meningkatkan hasil belajar mahasiswa yang terbukti signifikan dimana peningkatan tersebut terlihat dalam setiap siklus belajar.

\section{Simpulan}

Terdapat perbedaan Prestasi belajar Mahasiswa Akper Dharma Husada Kediri terhadap mata kuliah Anatomi dan Fisiologi Perkemihan dengan Metode Peer Teaching dan Konvensional. Pada metode pembelajaran Peer Teaching nilai yang didapat lebih baik yang menunjukkan saling bertukar informasi akan mampu meningkatkan pemahaman mahasiswa keperawatan dalam mempelajari anatomi.

\section{Saran}

Agar Penanggung Jawab Mata Kuliah (PJMK) dan dosen mengembangkan metode pembelajaran yang sesuai capaian pembelajaran, dalam hal ini lebih mengarah mahasiswa bekajar aktif mandiri.

Perlunya Wadah forum dosen untuk meningkatkan kemampuan dosen tentang metode-metode pembelajaran mahasiswa mandiri.

\section{Daftar Pustaka}

(2014). Kurikulum 2013 Akademi Keperawatan Dharma Husada
Kediri. Kediri: Akper Dharma Husada Kediri.

Ahmadi, A. (2005). Strategi Belajar Mengajar. Bandung: Pustaka Setia.

Allyn \& Bacon.

As'ari, A. R. (2001). Penggunaan Strategi Pemampatan dalam Pembelajaran Matematika. Jurnal MIPA. Tahun 30 (1): 1 -14.

Astika, D. P., \& Isroah. (2013). Implementasi Metode Belajar Peer Teaching untuk Meningkatkan Keaktifan Siswa dan Hasil Belajar. Yogyakarta: http://journal.uny.ac.id/index.php/jpakun /article/view/1678 diakses 8 Desember 2015.

Hermawan, I. (2015). Pengaruh Model Peer Teaching Terhadap Motivasi dan Hasil Belajar Keterampilan Hockey 52 Thesis. Universitas Pendidikan Indonesia: http://repository.upi.edu/14873/,diakses 5 januari 2016.

LPPM. (2014). Evaluasi Diri Akademi Keperawatan Dharma Husada Kediri. Kediri: Akper Dharma Husada Kediri.

Melitta D., (2012) Metode Pembelajaran Peer Teaching dan Problem Based Learning Untuk Memotivasi Sosialisasi dalam Kelas Pada Pembelajaran Statistika Di Universitas Bina Darma Palembang.

http://blog.binadarma.ac.id/dinamellita/? $\mathrm{p}=3$ diakses tanggal 2 Juni 2016

Slavin, R. (1990). Cooperative Learning : Theory, research and practice. Boston :

Suwono, H. 1999. Kualitas Proses dan Hasil Belajar Fungsi Darah melalui Metode Simulasi pada Siswa Kelas 5 SDN Bunulrejo V Malang. Chimera. Tahun 4 (1):21 -29.

Waluyanti, S. (2012). Kooperatif Jingsaw dan Peer Teaching sebagai Model Pembelajaran Mahasiswa Calon Guru. http://eprints.uny.ac.id/6282/MAKALA H_lemlit_2011.pdf diakses 6 Desember 2015. 